\title{
Preparation of $\alpha$-labeled aldehydes by base-catalyzed exchange reactions
}

\author{
Xavier Ariza $^{\mathrm{a},{ }^{*}}$, Guillermina Asins ${ }^{\mathrm{b}}$, Jordi Garcia ${ }^{\mathrm{a},{ }^{*}}$, Fausto G. Hegardt ${ }^{\mathrm{b}}$, Kamil \\ Makowski $^{\mathrm{a}}$, Dolors Serra ${ }^{\mathrm{b}}$, Javier Velasco $^{\mathrm{a}}$ \\ ${ }^{a}$ Departament de Química Orgànica and IBUB, Universitat de Barcelona, C/Martí i Franquès 1-11, 08028- \\ Barcelona (Spain) \\ ${ }^{\mathrm{b}}$ Departament de Bioquímica i Biologia Molecular (Fac. Farmàcia) and IBUB, Universitat de Barcelona, Barcelona \\ (Spain)
}

\begin{abstract}
s
A simple, efficient protocol for the preparation of $\alpha$-labeled aldehydes based on H/D or $\mathrm{H} / \mathrm{T}$ exchange catalyzed by 4-DMAP or $\mathrm{Et}_{3} \mathrm{~N}$ is described. High chemical yields and ratios of isotope incorporation were obtained even when small amounts $(\sim 1$ mmol) of aldehyde were used.
\end{abstract}

\section{Introduction}

In the course of our ongoing search for potential new drugs against obesity and type 2 diabetes, ${ }^{1}$ we required a sample of partially tritiated $\mathrm{C} 75$, an inhibitor of fatty acid synthase (FAS). This synthetic compound is used extensively in the study of fatty acid synthesis in metabolic disorders and cancer. ${ }^{2}$ Recently, Kuhajda et al. described the synthesis of $\left[5^{-3} \mathrm{H}\right]$ tritium labeled $\mathrm{C} 75$ from $\left[1-{ }^{3} \mathrm{H}\right]$ tritiated nonanal (see Scheme 1). ${ }^{3}$ Labeled aldehyde, in turn, was obtained in a two-step procedure by the reduction of nonanal with sodium $\left[{ }^{3} \mathrm{H}\right]$ borohydride $(15 \mathrm{mCi} / \mathrm{mmol})$ followed by re-oxidation with pyridinium chlorochromate. However, we sought a simpler protocol to label aldehydes, involving as little manipulation of radioactive tritium-labeled compounds as possible. ${ }^{4}$ In addition, the protocol should be applicable to a small amount of aldehyde.

Scheme 1. Synthesis of $\left[5^{3} \mathrm{H}\right]$ partially tritiated C75.

Acid- or base-catalyzed exchange of a protons in a carbonyl function by using $\mathrm{D}_{2} \mathrm{O}$ or diluted tritium oxide in water could meet these requirements of simplicity and compatibility with small scale. ${ }^{5}$ However, $\alpha$-tritiationlabeling of aldehydes is challenging due to the tendency of most such compounds to self-condense under acidic or basic conditions. Even if the extent of such aldol reactions was only moderate, purification of the crude, usually by distillation, would be necessary. ${ }^{6}$ For 
this reason, the reported protocols of exchange of a protons are not suitable for small amounts $\alpha$-labeled aldehydes. ${ }^{5 \mathrm{c}, \mathrm{d}}$ Thus, we studied the deuteration of nonanal, as a representative example of an enolizable aldehyde, with $\mathrm{D}_{2} \mathrm{O}$ under various conditions and catalysts. We now report here a simple, efficient protocol for the preparation of $\alpha$-deuterated aldehydes based on the H/D exchange catalyzed by $4-(\mathrm{N}, \mathrm{N}-$ dimethylamino)pyridine or $\mathrm{Et}_{3} \mathrm{~N}$. It should be noted that our results on $\mathrm{H} / \mathrm{D}$-exchange can also be extrapolated to low-level tritiation.

\section{Results and discussion}

As shown in Table 1, we carried out the deuteration of nonanal $(1,0.2 \mathrm{~mL})$ with $\mathrm{D}_{2} \mathrm{O}$ $(0.2 \mathrm{~mL})$ and a base $(10 \% \mathrm{~mol}$ eq. $)$ in a septum-sealed flask at a range of temperatures and times. After a few preliminary attempts, we obtained satisfactory results when the mixture of 1 and $\mathrm{D}_{2} \mathrm{O}$ was heated to $100{ }^{\circ} \mathrm{C}$ in the presence of $4-(\mathrm{N}, \mathrm{N}$ dimethylamino)pyridine (4-DMAP, $13 \mathrm{mg}$, entry 5) or $\mathrm{Et}_{3} \mathrm{~N}(22 \mathrm{~mL}$, entry 10) for $1 \mathrm{~h}$, or for $6 \mathrm{~h}$ at $70{ }^{\circ} \mathrm{C}$ (entry 1). ${ }^{7}$ The work-up was simple. Thus, to the mixture was added $\mathrm{CH}_{2} \mathrm{Cl}_{2}(4 \mathrm{~mL})$ and $1 \mathrm{M}$ aq. $\mathrm{HCl}(1 \mathrm{~mL})$ at $\mathrm{rt}$. The organic layer was then washed with aq. $\mathrm{NaHCO}_{3}$ and brine. The organic layer was dried $\left(\mathrm{MgSO}_{4}\right)$ and the solvent was carefully removed, to recover almost pure $1(80-90 \%)$ with $89 \%$ of deuterium incorporation. ${ }^{8}$ The reaction was successfully scaled up to $1 \mathrm{~mL}$ of nonanal (entry 6). However, longer reaction times at $100{ }^{\circ} \mathrm{C}$ led to the appearance of selfcondensation products (see entry 7). ${ }^{9}$

Table 1. $\alpha$-Deuteration of nonanal

The use of a stronger base such as 1,8-diazabicyclo[5.4.0]undec-7-ene (DBU) accelerated the deterioration of $\mathbf{1}$ by the formation of aldol by-products (entries 11 and 12). The use of less basic pyridine yielded a much lower percentage of deuterium incorporation (entry 13). Acidic catalysis was also less effective (entry 14). In addition, an attempt to use a 1:1 mixture of 4-DMAP and its hydrochloride or its acetate as catalyst failed (entries 15 and 16). ${ }^{10}$

Figure 1. Aldehydes 2-7.

Having in hand a convenient way to incorporate deuterium to nonanal, we extended our protocol to other representative $\alpha$-enolizable aldehydes. As shown in Table 2, satisfactoty results were recorded with $\alpha$-unbranched aldehydes $\mathbf{2}$ and $\mathbf{3}$ (entries 1 and 2) using 4-DMAP as catalyst, although $\mathrm{Et}_{3} \mathrm{~N}$ gave better yield in the deuteration of the more reactive aldehyde 4 . $^{11}$ Deuterium was incorporated to $\alpha$-branched aldehyde 5 in an excellent $95 \%$ extension only after $4 \mathrm{~h}$ whereas similar aldehyde 6 required only 1 h. Finally, every attempt to label phenylacetaldehyde $\mathbf{7}$ met with extensive polymerization, even under mild basic conditions. 
Table 2. $\alpha$-Deuteration of aldehydes 2-7

As far as the deuterium incorporation to $\alpha, \beta$-unsaturated aldehydes is concerned, enolization (path a in Scheme 2) could yield both $\alpha$ - and $\gamma$-labeled compounds. In addition, deuteration through conjugated addition of the catalyst (path $b$ in Scheme 2) is also feasible.

Scheme 2. Mechanism of deuteration of an $\alpha, \beta$-unsaturated aldehyde.

As expected, $\alpha$ - and $\gamma$-deuteration was noted in the 4-DMAP-catalysed treatment of aldehyde 8 at $100{ }^{\circ} \mathrm{C}$ for $1 \mathrm{~h}$ with deuterium oxide, as shown in Scheme 3. Commercial citral 9 (mixture of $\mathrm{E}$ and $\mathrm{Z}$ isomers) required $4 \mathrm{~h}$ for a similar level of deuteration. In contrast, 2-octynal 10 decomposed in basic media.

Scheme 3. Deuteration of $\alpha, \beta$-unsaturated aldehydes.

In conclusion, we have reported a simple but effective way to obtain deuterated or tritiated aldehydes from the unlabeled compound and the cheapest and more easily available label source, deuterium or tritium oxide. The method yields deuterated aldehydes that can be used for synthetic purposes without further purification. In addition, it is suitable for small quantities of aldehyde. When applied to tritiated materials, the minimum handling involved makes this protocol safer than other described in the literature.

\section{Acknowledgments}

We thank to the Universitat de Barcelona and Institut de Biomedicina de la Universitat de Barcelona (IBUB) for a doctorate studentship to K.M.

\section{References and notes}

1. P. Mera, A. Bentebibel, E. López-Viñas, A. G. Cordente, C. Gurunathan, D. Sebastián, I. Vázquez, L. Herrero, X. Ariza, P. Gómez-Puertas, G. Asins, D. Serra, J. Garcia, F. G. Hegardt, Biochem. Pharmacol. 2009, 77, 1084-1095.

2. More than a hundred citations can be found in the literature on the biological activity of $\mathrm{C} 75$ in recent years. For very recent references, see: (a) C. Rae, A. Graham, Diabetes Obes. Metab. 2008, 10, 1271-1274; (b) A. L. Cerrone-Szakal, 
N. A. Siegfried, P. C. Bevilacqua, J. Am. Chem. Soc. 2008, 130, 14504-14520. See also ref. 1.

3. F. P. Kuhajda, E. S. Pizer, J. N. Li, N. S. Mani, G. L. Frehywot, C. A. Townsend, Proc. Natl. Acad. Sci. USA 2000, 97, 3450-3454.

4. For a review on tritium labeling of organic compounds, see: M. Saljoughian, Synthesis 2002, 1781-1801.

5. (a) S. Buksha, G. S. Coumbarides, M. Dingjan, J. Eames, M. J. Suggate, N. Weerasooriya, J. Label. Radiopharm. 2006, 49, 757-771 and references therein. (b) C. Grison, S. Petek, P. Coutrot, Tetrahedron 2005, 61, 7193-7200. (c) For a very recent review on H/D exchange, see: J. Atzrodt, V. Derdau, T. Fey, J. Zimmermann, Angew. Chem. Int. Ed. 2007, 46, 7744-7765. (d) See also: A. Shulman, D. Sitry, H. Shulman, E. Keinan, Chem. Eur. J. 2002, 229-239.

6. (a) G. N. Reddy, C. J. Soares, M. J. Kurth, H. J. Segall, J. Label. Radiopharm. 1991, 29, 1257-1260; (b) S. B. Farren, E. Sommerman, P. R. Cullis, Chem. Phys. Lipids 1984, 34, 279-286. (c) W. Kirmse, H.-D. von Scholz, H. Arold, Justus Liebigs Ann. Chem. 1968, 711, 22-30.

7. The conjugated acids of $\mathrm{Et}_{3} \mathrm{~N}$ and 4-DMAP show a similar $p \mathrm{Ka}(\sim 9.1)$, see: (a) $\mathrm{F}$. G. Bordwell, Acc. Chem. Res. 1988, 21, 456-463. See also: (b) M. B. Smith, J. March, in Advanced Organic Chemistry 5th Edition; Wiley-Interscience: New York, 2001, pp. 327-362. However, an attempt at deuteration using $\mathrm{NaCN}$ ( $p \mathrm{Ka}$ $\mathrm{HCN}=9.2$ ) failed, and most of the aldehyde decomposed.

8. The deuterium incorporation was estimated by the integration value of the two alpha protons as they appeared in the ${ }^{1} \mathrm{H}$ NMR. Obviously, a second treatment of 1 with $\mathrm{D}_{2} \mathrm{O}$ would lead to $>98 \%$ of deuterium incorporation if is needed.

9. Almost complete transformation of nonanal into self-condensation products was observed when the mixture of the aldehyde and deuterated water was heated to $100{ }^{\circ} \mathrm{C}$ for $24 \mathrm{~h}$.

10.The existence of an important third-order term for the catalysis of the enolisation of aldehydes has been demonstrated. See: A. F. Hegarty, J. Dowling, J. Chem. Soc., Chem. Commun. 1991, 996-997. It has been argued that this third-order term is due to an alternative, concerted mechanism of enolisation in which both, a base and its conjugated acid play a role.

11. Our experience indicates that $\mathrm{Et}_{3} \mathrm{~N}$ acts as a milder catalyst that 4-DMAP in deuteration processes. However, 4-DMAP was our first choice, since some erratic results were obtained with $\mathrm{Et}_{3} \mathrm{~N}$, probably due to its volatility. 
Table 1. $\alpha$-Deuteration of nonanal

\begin{tabular}{|c|c|c|c|c|c|c|}
\hline \multirow[b]{2}{*}{ Entry } & (0. & HO $\frac{\mathrm{D}_{2} \mathrm{O}(}{\mathrm{cata}}$ & st, $\Delta$ aled flask & \multicolumn{2}{|c|}{$\underbrace{C H O}_{X Y Y}$} & \multirow[b]{2}{*}{$\begin{array}{c}\text { Self- } \\
\text { condensation } \\
\text { products }(\%)\end{array}$} \\
\hline & $\begin{array}{c}\text { Catalyst } \\
(0.1 \text { equiv })\end{array}$ & Temperature & Time & $\begin{array}{c}\text { Recovered } \\
\text { nonanal }(\%)\end{array}$ & $\begin{array}{c}\text { Deuterium } \\
\text { incorporation } \\
(\%)\end{array}$ & \\
\hline 1 & 4-DMAP & $70{ }^{\circ} \mathrm{C}$ & $6 \mathrm{~h}$ & 86 & 90 & $<1$ \\
\hline 2 & 4-DMAP & $90{ }^{\circ} \mathrm{C}$ & $1 \mathrm{~h}$ & 93 & 80 & $<1$ \\
\hline 3 & 4-DMAP & $100^{\circ} \mathrm{C}$ & $10 \min$ & 88 & 51 & $<1$ \\
\hline 4 & 4-DMAP & $100^{\circ} \mathrm{C}$ & $20 \mathrm{~min}$ & 85 & 60 & $<1$ \\
\hline 5 & 4-DMAP & $100^{\circ} \mathrm{C}$ & $1 \mathrm{~h}$ & 90 & 89 & $<1$ \\
\hline $6^{\mathrm{a}}$ & 4-DMAP & $100^{\circ} \mathrm{C}$ & $1 \mathrm{~h}$ & 95 & 89 & $<1$ \\
\hline 7 & 4-DMAP & $100^{\circ} \mathrm{C}$ & $2 \mathrm{~h}$ & 68 & 93 & 4 \\
\hline $8^{b}$ & $\begin{array}{l}\text { 4-DMAP/ 4- } \\
\text { DMAP } \mathrm{HCl}\end{array}$ & $100^{\circ} \mathrm{C}$ & $1 \mathrm{~h}$ & 85 & 89 & $<1$ \\
\hline 9 & $\mathrm{Et}_{3} \mathrm{~N}$ & $100^{\circ} \mathrm{C}$ & $20 \mathrm{~min}$ & 80 & 56 & $<1$ \\
\hline 10 & $\mathrm{Et}_{3} \mathrm{~N}$ & $100^{\circ} \mathrm{C}$ & $1 \mathrm{~h}$ & 80 & 89 & $<1$ \\
\hline 11 & DBU & $100{ }^{\circ} \mathrm{C}$ & $20 \min$ & 69 & 68 & 22 \\
\hline 12 & DBU & $100{ }^{\circ} \mathrm{C}$ & $1 \mathrm{~h}$ & 60 & 73 & 26 \\
\hline 13 & pyridine & $100{ }^{\circ} \mathrm{C}$ & $1 \mathrm{~h}$ & 95 & $<5$ & $<1$ \\
\hline 14 & $p$-TsOH & $100{ }^{\circ} \mathrm{C}$ & $1 \mathrm{~h}$ & 83 & 56 & 4 \\
\hline 15 & 4-DMAP·HCl & $100^{\circ} \mathrm{C}$ & $1 \mathrm{~h}$ & 97 & $<5$ & $<1$ \\
\hline 16 & 4-DMAP'AcOH & $100^{\circ} \mathrm{C}$ & $1 \mathrm{~h}$ & 95 & $<5$ & $<1$ \\
\hline
\end{tabular}

${ }^{\mathrm{a}}$ Reaction using $1 \mathrm{~mL}$ of aldehyde and $1 \mathrm{~mL}$ of $\mathrm{D}_{2} \mathrm{O}$

${ }^{\mathrm{b}} 1: 1$ Mixture of 4-DMAP and its hydrochloride. 
Table 2. $\alpha$-Deuteration of aldehydes 2-7 $(0.2 \mathrm{~mL} / 0.2 \mathrm{~g})$ with $\mathrm{D}_{2} \mathrm{O}(0.2 \mathrm{~mL})$ at 100 ${ }^{\circ} \mathrm{C}$.

\begin{tabular}{cccccc}
\hline Entry & Aldehyde & $\begin{array}{c}\text { Base } \\
(0.1 \text { equiv })\end{array}$ & Time & $\begin{array}{c}\text { Yield } \\
(\%)\end{array}$ & $\begin{array}{c}\text { Deuterium } \\
\text { incorporation } \\
(\%)\end{array}$ \\
\hline 1 & $\mathbf{2}$ & 4-DMAP & $1 \mathrm{~h}$ & 98 & 93 \\
2 & $\mathbf{3}$ & 4-DMAP & $1 \mathrm{~h}$ & 75 & 85 \\
3 & $\mathbf{4}$ & $\mathrm{Et}_{3} \mathrm{~N}$ & $1 \mathrm{~h}$ & 77 & 91 \\
4 & $\mathbf{5}$ & 4-DMAP & $1 \mathrm{~h}$ & 80 & 89 \\
5 & $\mathbf{5}$ & 4-DMAP & $4 \mathrm{~h}$ & 72 & 95 \\
6 & $\mathbf{6}$ & 4-DMAP & $1 \mathrm{~h}$ & 97 & 95 \\
7 & $\mathbf{7}$ & Et ${ }_{3} \mathrm{~N}$ & 20 & $<5$ & - \\
& & & $\mathrm{min}$ & & \\
\hline
\end{tabular}

